\title{
Impact of PLM system in the New Food Development process performances: an empirical research
}

\author{
Claudia Pinna ${ }^{1}$, Laureline $\mathrm{Plo}^{2,3}$, Monica Rossi ${ }^{1}$, Vincent Robin ${ }^{3}$, Sergio Terzi ${ }^{1}$ \\ ${ }^{1}$ Politecnico di Milano, Department of Management, Economics and Industrial \\ Engineering Piazza Leonardo da Vinci, 20133, Milan, Italy \\ claudia.pinnalpolimi.it, monica.rossiepolimi.it, \\ sergio.terzi@polimi.it \\ ${ }^{2}$ Groupe POULT - Site de Montauban, France \\ 1.plo@groupe-poult.fr \\ ${ }^{3}$ IMS laboratory, University of Bordeaux, Talence, France \\ vincent.robin@u-bordeaux.fr
}

\begin{abstract}
Over the last years, the food industry has become increasingly more relevant since it represents excellence not only at the European level but also for the worldwide economy. Starting from this consideration, the main objective of this paper is to provide some elements that could support food companies to be successful on the market. In 2016, during the last PLM conference, first results of a wider research have been presented with the aim to understand how the PLM solution is adopted in the food industry, limits and challenges of its deployment in this sector. This paper presents how the study has evolved over this year. Starting from this point, the impacts and effects of the use of the PLM solution on the New Food Development (NFD) process performances have been described. To identify these effects, a questionnaire has been developed, and used as a framework to support the data gathering process. The different sections of the questionnaire will be described in the paper. Furthermore, the results of a preliminary empirical research based on a case study have been shown. The results of this work will help both food companies and PLM vendors. Indeed, it will support PLM vendors to understand the food industry vision about their NFD process and performances. On the other hand, food companies will be able to better understand their NFD process, their NFD process performances and how they can use the PLM solution to affect their performances.
\end{abstract}

Keywords: New Product Development (NPD), Product Lifecycle Management (PLM), Food Industry, New Food Development (NFD), PLM for the Food Industry, NFD process performances

adfa, p. 1, 2011.

(C) Springer-Verlag Berlin Heidelberg 2011 


\section{Introduction}

Food sector is considered as one of the most important sector of the current economy [1]. Despite this fact, food companies have to face several challenges in order to maintain and to increase their competitive advantage on the market [2][3][4]. This paper starts from the results obtained in a previous study [5], presented during the PLM16 conference and we complete them with results of a pilot case. The aim of the previous study was to estimate if the PLM solution is adopted in the New Food Development (NFD) process. In order to achieve this objective, we focused on: the level of knowledge of the PLM solution in this sector (both from the literature and from the practitioners' point of views), the main phases and activities characterizing the NFD process (thanks to an empirical research, made through several case studies) and the PLM functionalities supporting the NFD process. This paper presents how the study has evolved over this year. As the first step of our research was the analysis of the adoption of PLM in NFD, the second step is the analysis of impacts and effects of the use of the PLM functionalities on the NFD performances. To identify these effects a questionnaire that is a framework supporting the data gathering process, has been developed, putting in evidence the NFD activities performances and how the PLM functionalities support the NFD process. The questionnaire was developed to be sent to those food companies that are currently using the PLM functionalities supporting their NFD from at least three years, in order to verify the obtained benefits after the implementation of the solution. Before to be sent to those companies, the questionnaire has to be tested and validated in order to be sure that the tool is fully aligned with the defined expectations. In this paper we present the results of the first pilot case, with the support of Poult [6] (a French company). Thanks to this pilot case, the questionnaire has been revised and updated, in order to be ready to be submitted to the others food companies of the sample. The paper starts with a literature review about the level of knowledge of the PLM solution in the food sector. After that, the following section is dedicated to a preliminary empirical research in which we define our research methodology, the meaning and the scope of the different parts of the proposed questionnaire. In section 4, we present the results of a Pilot Case developed with the aim to test our questionnaire. Section 5 is dedicated to the discussion of the pilot case results. Finally, session 6 concludes the paper, presenting some thoughts and future researches.

\section{State of the art on the knowledge of the PLM solution in the food sector}

This first section of the paper adopts a qualitative methodology based on a literature review. The aim of the review is to understand the level of knowledge of the PLM solution in the food sector from the scientific point of view. The whole review process is summarized in Figure 1. 


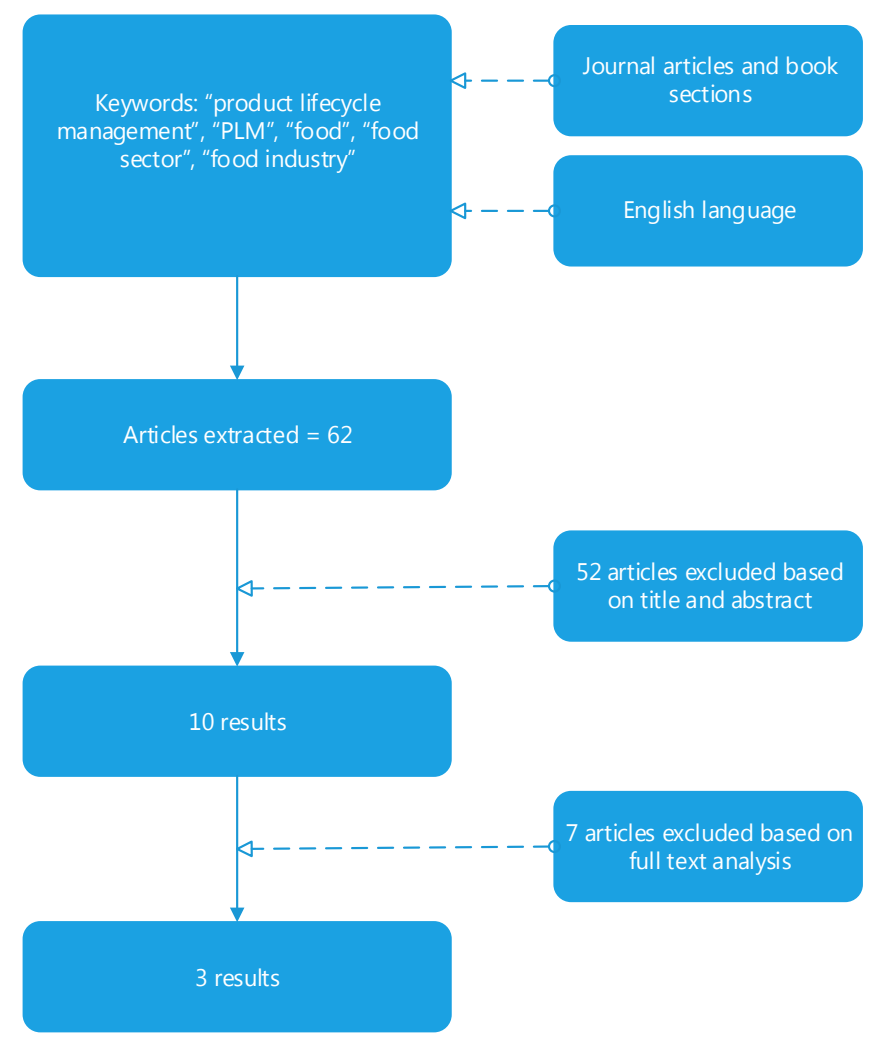

Fig. 1. Structure of methodology adopted for literature review

The literature review has been performed following three main steps: (i) to identify the keywords to be used (and the rules to combine them) in order to investigate the topic, (ii) to choose which sources of databases have to be used for the research and (iii) to analyse the results found by the combination of the different keywords.

Starting from the first step, three clusters of key words have been chosen and applied to retrieve the articles of interest. The first group consists on the following keywords: "Product Lifecycle Management", "PLM" while the second one is composed by the following: "Food industry", "Food sector" and "Food". Each keyword of any group was then combined in the search with one of each group, in order to expand the research results as much as possible. The searches were done separately for each keyword applied to the journals' abstracts, title and keywords in each specific search engine. Besides Authors did not set any restrictions related to time, but did it for type, including only article and book sections.

Furthermore, concerning the second step of the research, two different abstract and citation databases of peer-reviewed literature have been selected: Scopus and Sciencedirect. In this regard 62 articles have been collected, that become 52 after having remove duplicates. The abstracts of the remained articles and book sections have been carefully read to assess criteria for relevance and exclude articles that used those words in another semantic way. After evaluation of the abstracts, 10 studies remained in the 
final selection of articles (the others were "out of topic"). These articles were extracted and read thoroughly in full length. Only 3 articles were at the end considered aligned with the field of interest.

\subsection{Literature Review results}

The 3 interesting articles give a generic overview of how food companies could benefit from the use of the PLM solution. In fact, a complete discussion about how the PLM functionalities are used in the food industry has not yet been treated in the literature.

Both the Overbosch and Blanchard [7] and the Granros [8] works dealing with the PLM solution on the Quality and Food Safety Management (focus on regulatory compliance) topics. These works show also some possible benefits for food companies after the implementation of this solution, focusing specifically on the quality aspects.

Pinna et al. [5] propose a list of PLM functionalities supporting the product development process activities for the food industry. Furthermore, this study gives a brief overview, through a case study analysis, about how much food companies use IT solutions, including also the PLM solution, to support the NFD process.

The literature review results clearly show the presence of a literature gap in this field. This assumption is strongly confirmed by the fact that over 53 articles found, only 3 were interesting, and this mean a lack of knowledge. Furthermore, no articles dealing with the use of the PLM solution in the food industry have been found. This is the reason why this study want to start to address this topic.

\section{A preliminary empirical research}

\subsection{Theoretical framework and research questions}

The main objective of the whole study is to understand how the use of the PLM functionalities impact on the NFD process performances. To achieve this aim, we proposed a methodology based on four different activities that allows us to put in evidence different kinds of impact at different levels in the company (strategy of the company, its activities with an organizational and operational visions and its performances):

- A1: to identify the main Critical Success Factors (CSF) driving the company strategy supporting the NFD process;

- A2: to identify which are the main performances evaluating the NFD activities;

- A3: to understand how PLM functionalities support the NFD activities;

- A4: to identify how PLM functionalities impact on the identified performances.

Therefore, to provide an answer to each of these actions, a questionnaire has been developed, dedicating one specific section to each of them.

Figure 2 shows the theoretical framework and the logic sequence (steps 1 to 5) to develop the 4 different sections of the questionnaire. 


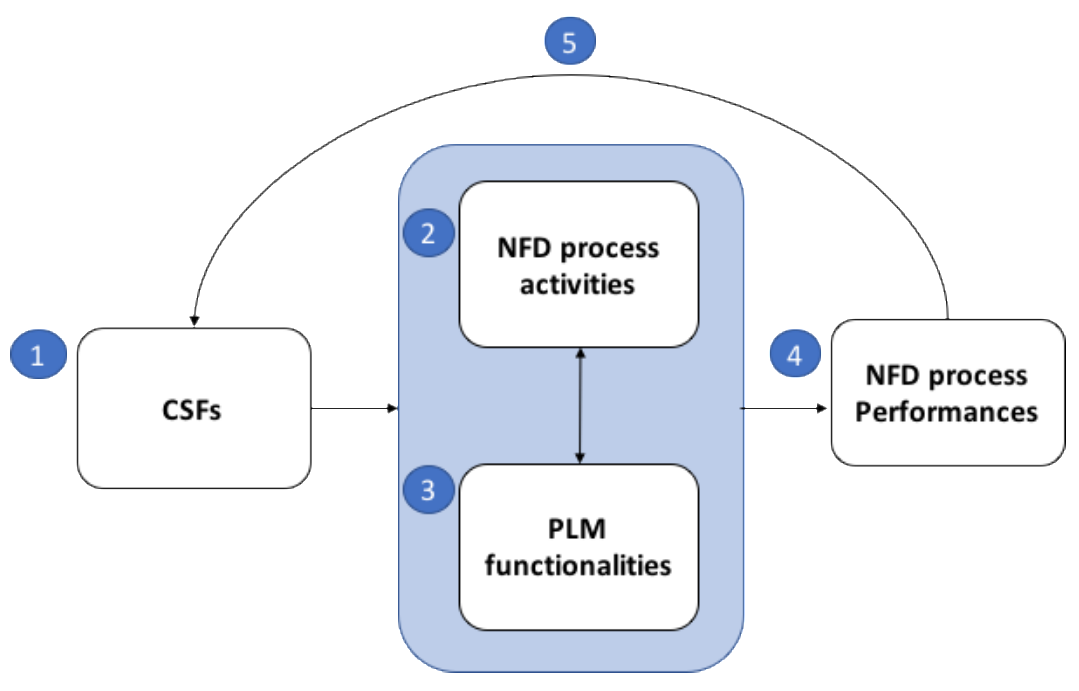

Fig. 2. - Research theoretical framework

The first step consists on the identification of the CSFs that are leading the strategy of the company. The step 2 allows us to analyse the PD process and its coherence with the strategy. Step 3 is focused on the links between activities of PD process and the PLM functionalities, to investigate both process and information management. Finally, in step 4, NFD performances are identified, trying also to understand the possible influence that PLM functionalities could have on them. Thanks to such a methodology we obtain a vision of:

- the strategy of the company;

- the way to "translate" this strategy in real activities in the PD process;

- the influences and impacts of PLM on these activities and on the related performances.

Starting from these assumptions, it is possible to identify one main Research Question and 4 main Research Sub-Questions that correspond to each section of the questionnaire (Table 1).

Table 1. Main Research Question and Research Sub-Questions

RQ: How do PLM functionalities impact on the NFD process performances?

$\boldsymbol{s R Q 1}$ Which are the main Critical Success Factors (CSF) driving the company strategy?

SRQ2 Which are the main performances evaluating NFD activities?

$\boldsymbol{S R Q 3}$ How do PLM functionalities support NFD activities?

sRQ4 How do PLM functionalities impact on the identified performances? 


\subsection{Methodology - research strategy}

In this work Case Study is utilized as a research strategy [9]. A multiple embedded case study will be developed, considering several companies within food industry. Specifically, the companies belonging to the sample must respect the following characteristics:

- They must by classified as "big companies". In fact, large companies have a more formalized and structured NPD process. In addition, being the PLM solution costly for companies, it is largely used by large companies rather than small ones;

- They must use a PLM solution to manage their NFD process activities.

As said before, questionnaire has been used as a research tool. It has been developed between September and November 2016. In December 2016, it has been tested and validated through a Pilot Case. Moreover, in January 2017, the sample of food companies to be interviewed has been defined.

The selected sample is made up of about 20 companies. In order to have a complete view of how the PLM solution is used to support the NFD process, it has been decided to interview those actors who mostly interfaces with this solution, and so managers belonging to the R\&D and the IT functions. The phase of contact request with companies is a delicate phase, as it is not easy to find the right people to be interviewed and above all to obtain their availability. During this phase, our collaboration with a PLM vendor leader in the food industry will be very important to obtain the case studies appropriate to the analysis. This cooperation allows us to have a direct contact with their customers, streamlining the research process.

The questionnaire will be submitted in the form of interview. A standard protocol will be followed and it will be valid for all the case studies. It will allow the interviewer to guide the discussion by addressing specific topics.

The interview process will take place from January 2017 until June 2017, after which it will be followed by the analysis of the obtained results.

Case studies typically involve multiple sources of information [10]. In this research, the sources of information will be:

- one questionnaire, which will be used as a guideline for as many semi-structured interviews with the company's managers (IT and R\&D managers);

- a generic model of NFD process performances and its management that will instanced for each company;

- a map presenting relations between PLM functionalities and NFD activities but also between functionalities and the identified performances.

As mentioned before, in order to validate and to test the questionnaire a first pilot case has been developed, with the aid of Poult, an important French company that is currently using a PLM solution to support their R\&D process. Once the questionnaire has been validated and refined, it will be emailed to the company's IT and R\&D managers, and will be answered through an interview. Results collected from the interview will be elaborated and submitted to the company's managers for approval. In conclusion, the results obtained from the case studies will be validated by the company's top management. In the next section, we present results of our pilot case. 


\section{Pilot Case: the Poult group}

A pilot case study helps to refine the data collection plans with respect to both the content of the data and the procedures to be followed [11]. It is formative, assisting to develop relevant lines of questions (possibly even providing some conceptual clarification for the research design as well) [11]. For these reasons, it is important to explain the "Selection of the Pilot Case" (Why have I chose this pilot case?) and the "Scope of the Pilot Inquiry".

Concerning the first question, Poult has been chosen as Pilot Case because this company has engaged a reflexion about the interest to use PLM to manage its NFD process and has the habit to work with researchers according to research methodologies (a PhD student is working in the company in collaboration with the University of Bordeaux). $\mathrm{PhD}$ student and researchers of the University of Bordeaux were already collaborating right on the PLM topic (they helped Poult in the phase of PLM suppliers' selection and of the solution implementation) and due to this fact, they have an easy access to the case. The company was also selected because a study on their NFD process, on their information management and on the actors involved in the process had already been carried out (with the aim to understand which PLM solutions better fit with their product development process). About the scope of the Pilot Inquiry this pilot case has been chosen to improve its conceptualization of different types of PLM functionalities, of different NFD performances and their related organizational effects.

\subsection{Critical Success Factors (CSF)}

The first step of our proposition to understand how the use of the PLM functionalities impacts on the New Food Development (NFD) process performances is the identification of CSFs. CSFs are a limited number of key variables or conditions that have an impact on how successfully and effectively an organization meets its mission or the strategic goals of a program or project. CSFs are used to define key areas of activity and the strategic indicators of the company [12]. These strategic indicators allow us to evaluate the "strategical interest" of the deployment of PLM solution in a company. As Poult wants to reduce the answer time to a customer need and to ensure better continuity between the "product" innovations and their putting into production, company considers that its CSF are:

- the sharing of information by setting up a unique product repository enabling the company to maintain centralized, reliable and up-to-date information;

- the optimization of its processes by sharing and capitalizing on knowledge;

- the deploying a structured methodology; to develop new product;

- the analysis and the anticipation of the risks linked to the product/process data.

\subsection{NFD phases and activities}

In our previous work [5], we identified the main generic phases and activities characterizing the NFD process thanks to analysis of different case studies. The NFD phases previously identified characterize a standard process. As the different sections of our 
questionnaire are linked with the phases and activities of the NFD process we have to check, for each company which will be interviewed, if "the same language is spoken" and if the questionnaire is coherent. Tables 2 presents the process phases and activities of Poult and Table 3 puts in evidence similarities and differences between the standard process and the "real" process of Poult. This step is an obligation to contextualize our questionnaire and before starting analysing of its different sections.

Table 2. NFD process phases and activities of Poult and actors involved

\begin{tabular}{lll}
\hline \multicolumn{1}{c}{ NFD macro-phase } & \multicolumn{1}{c}{ NFD activities } & \multicolumn{1}{c}{ Actors } \\
\hline $\begin{array}{l}\text { Customer's or internal } \\
\text { (Poult's project) re- } \\
\text { quest for proposal }\end{array}$ & $\begin{array}{l}\text { Send external NFD request } \\
\text { Send internal NFD request } \\
\text { Receive customer or internal } \\
\text { request and carry out a pre- } \\
\text { liminary study }\end{array}$ & $\begin{array}{l}\text { Customers } \\
\text { General (innovation challenge) } \\
\text { Marketing } \\
\text { "Product family" (R\&D, market- } \\
\text { ing, trade, production }\end{array}$ \\
\hline Project launch & $\begin{array}{l}\text { Plan the project } \\
\text { Develop the recipe }\end{array}$ & $\begin{array}{l}\text { R\&D (Project Manager) } \\
\text { General (innovation challenge) }\end{array}$ \\
\hline \multirow{2}{*}{$\begin{array}{l}\text { Product Test \& Feasi- } \\
\text { bility }\end{array}$} & $\begin{array}{l}\text { Test recipe (Lab and Indus- } \\
\text { trial Testing) }\end{array}$ & $\begin{array}{l}\text { R\&D (Project Manager + R\&D } \\
\text { technician) }\end{array}$ \\
\hline $\begin{array}{l}\text { Study internal feasibility } \\
\text { Study external feasibility }\end{array}$ & $\begin{array}{l}\text { Production } \\
\text { Customer Laboratory }\end{array}$ \\
\hline
\end{tabular}

Table 3 shows the comparison between the standard process identified in the previous study [5] and the NFD process of Poult.

Table 3. Comparison between our standard process and Poult NFD process (Y: correspondence, $\mathrm{N}$ : difference)

\begin{tabular}{lll}
\hline \multicolumn{1}{c}{ NFD macro-phase } & \multicolumn{1}{c}{ NFD activities } & \multicolumn{1}{c}{ Y/N } \\
\hline \multirow{2}{*}{ Planning } & Plan the project & $\begin{array}{c}\text { No, unless developing a new product is } \\
\text { a result of an internal need (exceptional } \\
\text { case: the need usually arises from a } \\
\text { customer) }\end{array}$ \\
\cline { 2 - 3 } & Define the recipe & $\begin{array}{c}\text { No, unless developing a new product is } \\
\text { a result of an internal need (exceptional } \\
\text { case: the need usually arises from a } \\
\text { customer) }\end{array}$ \\
\hline \multirow{3}{*}{$\begin{array}{ll}\text { Recipe Definition } \\
\text { Product Test \& Feasi- } \\
\text { bility }\end{array}$} & $\begin{array}{l}\text { Study Idea Internal Fea- } \\
\text { sibility }\end{array}$ & No \\
\cline { 2 - 3 } & Develop the Recipe & Yes \\
\cline { 2 - 3 } & $\begin{array}{l}\text { Study Recipe Internal } \\
\text { Feasibility }\end{array}$ & Yes \\
\cline { 2 - 3 } & $\begin{array}{l}\text { Study Product internal } \\
\text { feasibility }\end{array}$ & Yes \\
\cline { 2 - 3 } & &
\end{tabular}




\begin{tabular}{lll}
\cline { 2 - 3 } & $\begin{array}{l}\text { Study Product external } \\
\text { feasibility }\end{array}$ & Yes \\
\hline Industrialization & Industrialize & No \\
\hline $\begin{array}{l}\text { Production, Launch } \\
\text { and Commercialization }\end{array}$ & $\begin{array}{l}\text { Manufacture, Launch } \\
\text { and Commercialize }\end{array}$ & Yes \\
\hline
\end{tabular}

On the whole, the description of NFD process proposed seems to be similar to the Poult's one but we observe some differences on the first two phases:

- Plan the project: Poult Company mainly sells its products under private label, that is to say that it is the retailers that impose their idea and define their need. Company in-house teams reflect on the product to be created, so that it adapts to our customers' strategy (mainly the retailer). Thus, the macro phase planning is mainly generated when they enter a process of development of a new product following a need expressed internally (either by the marketing department after market study or after the innovation challenge conducted internally). In the case of an internal need, company is a source of proposal and once the product is created, it is presented to the identified customers (retailers);

- Define Recipe: A first estimation of the technical and financial feasibility is carried out during phase 0 and then another during the definition of the recipe. In addition, the industrialization phase is carried out in parallel with the production phase and feasibility tests. In general, the production manager checks whether the manufacturing line can manage the production of the new product with all its technical and financial characteristics or not. Once the project team seems to agree, a small quantity of products (industrial tests or laboratories) is generally produced to check everything is okay before sending the samples produced to the customer and / or panel. If the customer seems satisfied with the products sent then the product is ready to be launched on the market.

Once the various phases characterizing the Poult NFD process and the gap from the general process have been identified, it will be possible to go on with the identification of performances [13].

\subsection{Main performances characterizing the NFD activities}

The main objective of this section is to understand how the food companies evaluate their NFD activities and how they define "what is performance for NFD process". The results obtained through this analysis will help food companies to better understand their NFD activities, their NFD process performances and to support companies in monitoring the same activities over the time. Mapping the KPIs characterizing each activity and assigning a grade of importance to each of them will allow to understand which the most relevant NFD activities are for companies (classified as "value added activities". In this context, it will be possible to mostly focus on these relevant categories, because they are those that confer greater value to the whole process.

In the specific Poult case, measuring performance in the company remains an open question where opinions are multiple and shared. The most widely used indicators within the Poult Group remain in production (overall rate of return) and at the level of supply chain (customer satisfaction). In R\&D, the main objectives of a project are to 
reduce development time and costs. For this purpose, R\&D has not developed indicators, but it has more general indicators on projects: for example, the number of products that have emerged, the percentage of projects carried out in relation to the number of projects undertaken. The indicator remaining the most important for R\&D remains the rate of satisfaction of the tasting panels concerning the new products or the follow-up of the products already referenced (Table 4).

Table 4. Poult NFD process activities and related performances

\begin{tabular}{|c|c|c|}
\hline NFD activities & NFD process performances & Relevance \\
\hline $\begin{array}{l}\text { Study Product internal fea- } \\
\text { sibility }\end{array}$ & $\begin{array}{l}\text { Indicator Tracking panels referenced products } \\
\text { Indicators panels new referencing } \\
\text { Customer satisfaction rate = Total satisfactory } \\
\text { panels / Total panels received }\end{array}$ & 4 \\
\hline $\begin{array}{l}\text { Study Product external fea- } \\
\text { sibility }\end{array}$ & $\begin{array}{l}\text { The percentage of projects carried out in relation } \\
\text { to the number of projects undertaken }\end{array}$ & 3 \\
\hline $\begin{array}{l}\text { Manufacture, Launch and } \\
\text { Commercialize }\end{array}$ & $\begin{array}{l}\text { Production: } \\
\text { TRG is the product of } 3 \text { rates. } \\
\text { TRG = availability rate (TD) x efficiency rate } \\
\text { (TE) x quality rate (TQ) } \\
\text { Supply chain: } \\
\text { Litigation: number of lines in dispute / total } \\
\text { number of order lines Delivered during the same } \\
\text { period... }\end{array}$ & 3 \\
\hline
\end{tabular}
scale: $1=$ Not important; 2 =Low importance; $3=$ Important; $4=$ Very important

\subsection{How do PLM functionalities support NFD activities?}

According to the results obtained in 2016 [5], in this study 9 main PLM functionalities, supporting the NFD process, are taken into consideration. In this context, these functionalities are considered as a metrics of classification. Starting from these assumptions, we present here the results related to a section of the questionnaire (Table 5). The main objective of this section is to understand how PLM functionalities support the different NFD activities. The results obtained will help food companies to better understand the potentiality of the PLM categories and where these functionalities have an impact on the NFD process activities. In fact, to use properly PLM functionalities, food companies have first of all to understand the meaning and the potentialities of each of them and then to understand which activities of NFD process are supported. The knowledge about the main process activities and about how the PLM functionalities support the analysed activities will allow food companies to maximise the benefits of the adopted solution.

Table 5. PLM functionalities and NFD main activities, the Poult Pilot Case

\begin{tabular}{ccc}
\hline PLM functionalities & NFD main activities supported & Actors Involved (BU) \\
\cline { 2 - 3 }$C A D$ design management & Not used & - \\
\hline$C A D$ for packaging design & Not used & - \\
\hline
\end{tabular}




\begin{tabular}{|c|c|c|}
\hline $\begin{array}{l}\text { Formula and recipe man- } \\
\text { agement }\end{array}$ & Develop Recipe & R\&D (Project Manager) \\
\hline Label management & Study Product Internal Feasibility & $\begin{array}{c}\text { R\&D (Project Manager) } \\
\text { Quality }\end{array}$ \\
\hline PLM team collaboration & Not used & - \\
\hline $\begin{array}{l}\text { Product portfolio and pro- } \\
\text { gram management }\end{array}$ & Not used & - \\
\hline $\begin{array}{c}\text { Report specific to the indus- } \\
\text { try }\end{array}$ & $\begin{array}{l}\text { Study Product Internal Feasibility } \\
\text { Study Product External Feasibility }\end{array}$ & $\begin{array}{l}\text { R\&D (Project Manager) } \\
\text { Quality }\end{array}$ \\
\hline Regulatory compliance & $\begin{array}{c}\text { Develop Recipe } \\
\text { Study Product internal feasibility }\end{array}$ & $\begin{array}{c}\text { R\&D (Project Manager) } \\
\text { Quality } \\
\end{array}$ \\
\hline Specifications management & Not used & - \\
\hline
\end{tabular}

\subsection{Relation between PLM functionalities and NFD process performances}

Finally, once both Value Added (VA) activities and PLM functionalities have been identified, it will be possible to define the influence that each functionality has on each performance. In particular, the most interesting part for companies will be to focus on the value-added activities previously identified. In this way, companies can understand which are the performances that mostly represent their process and which must be kept under control. After that, thanks to the relation between PLM functionalities and NFD activities it will be possible to identify the link between them. In this way, companies can select the PLM functionalities which mainly influence their value-added activities and, thanks to the monitoring of the related performances, it will be possible to know the relative impact. This final step will allow food companies to better understand how they can use these functionalities in order to improve their NFD activities and consequently trying to achieve the main goals defined by the CSFs previously identified. Moreover, in order to achieve best results, it is necessary that those who use the software functionalities have full knowledge of the tools they are using, having understood also the relative capacities and potentialities. In the table below the results related to the Poult Pilot Case are presented (Table 6). The relation between PLM functionalities and performances could be positive, negative or none: positive relation means that the use of the PLM functionalities has improved the performances, negative relation that the use of the PLM functionalities has decreased the performances and no relation means that the use of the PLM functionalities has no influence on the performances.

Table 6. Evaluation of the impact of PLM software categories on NFD process performances, the Poult's results

\begin{tabular}{clc}
\hline NFD activities & \multicolumn{1}{c}{ PLM functionalities } & NFD process performances \\
\hline Develop Recipe & $\begin{array}{l}\text { Formula and recipe man- } \\
\text { agement } \\
\text { Regulatory compliance }\end{array}$ & No performance measured \\
\hline Make a Prototype & $\begin{array}{l}\text { No PLM functionality sup- } \\
\text { ports this activity }\end{array}$ & No performance measured \\
\hline $\begin{array}{l}\text { Study Product in- } \\
\text { ternal feasibility }\end{array}$ & $\begin{array}{l}\text { Label management } \\
\text { Report specific to the in- } \\
\text { dustry } \\
\text { Regulatory compliance }\end{array}$ & $\begin{array}{l}\text { The percentage of projects carried out in } \\
\text { relation to the number of projects under- } \\
\text { taken }\end{array}$ \\
\hline
\end{tabular}




\begin{tabular}{|c|c|c|}
\hline $\begin{array}{l}\text { Study Product ex- } \\
\text { ternal feasibility }\end{array}$ & $\begin{array}{l}\text { Report specific to the in- } \\
\text { dustry }\end{array}$ & $\begin{array}{l}\text { Indicator Tracking panels referenced } \\
\text { products } \\
\text { Indicators panels new referencing } \\
\text { Customer satisfaction rate }= \\
\text { Total satisfactory panels / Total panels } \\
\text { received }\end{array}$ \\
\hline $\begin{array}{l}\text { Manufacture, } \\
\text { Launch and Com- } \\
\text { mercialize }\end{array}$ & & $\begin{array}{c}\text { Production: } \\
\text { TRG is the product of } 3 \text { rates. } \\
\text { TRG = availability rate (TD) x efficiency } \\
\text { rate (TE) x quality rate (TQ) } \\
\text { Supply chain: } \\
\text { Litigation: number of lines in dispute / } \\
\text { total number of order lines Delivered } \\
\text { during the same period }\end{array}$ \\
\hline \multicolumn{3}{|c|}{$\begin{array}{l}\text { For this specific case, the analysis has to be restrict to the information that Poult } \\
\text { shlights as important. In fact, only } 2 \text { of the NFD activities are both supported by PLM } \\
\text { actionalities and measured thought performance indicators. These phases are: "study } \\
\text { oduct internal feasibility" and "study product external feasibility". Unfortunately, it } \\
\text { not possible to assign a relation between use of PLM functionalities and NFD per- } \\
\text { mances because these PLM functionalities have been deployed in the Poult group } \\
\text { ently. Thus, the company is not in position to establish a precise analysis on the } \\
\text { ations between the introduction of a PLM solution and the NFD process. Neverthe- } \\
\text { s, they assume that the implementation of a PLM within the Poult Group will influ- } \\
\text { ce the processes and particularly the activities carried out within the R\&D and quality } \\
\text { vices. Indeed, the construction of a single raw materials database will make it easier } \\
\text { research and use the data during the formulation phases. Improved data quality on } \\
\text { materials results in less error in formulation. Within the quality department, the } \\
\text { plementation of a PLM tool will allow to automatically generate documentation re- } \\
\text { ed to the product/process from the data entered in the repository, formulating. }\end{array}$} \\
\hline
\end{tabular}

\section{$5 \quad$ Research Results discussion}

The Poult Pilot Case has to help us to test, to validate and to refine the first version of the questionnaire. In this concern, different changes have been done to the preliminary version proposed:

- CSFs section has been moved: in the first version of the questionnaire this section was positioned at the end. Speaking with those who were interviewed, they proposed to move this section at the beginning in order to have a more complete view of the company, going also to define the strategical objectives and trying to link the next sections keeping in mind these information;

- NFD process comparison: a question about the comparison between the general NFD process proposed and the current one of the company has been introduced, in order to better contextualize and customize the questionnaire based on the interviewed company;

- Link between CFSs and NFD performances: this section has been deleted because it doesn't add relevant information to the main Research Question defined. 
The other sections of the questionnaire were aligned with the Poult point of view, so it was decided in some case to improve the quality of the questions, in terms of presentation, but the meanings have not been changed. Concerning the Poult Case Study, what it could be said is that the main phases that have to be taken under consideration are the internal and external studies of product feasibility. These phases are managed with the support of some PLM functionalities, as Label management, Report specific to the industry and Regulatory compliance. In order to measure the performances of these activities three performances have been identified: the percentage of projects carried out in relation to the number of projects undertaken, the indicator tracking panels referenced products and indicators panels new referencing. Being a pilot case, the fact that it was not possible to identify a relation between PLM functionalities and NFD performances is not so relevant, because of the main scope of the inquiry. Indeed, as said before, the scope of the pilot case is not data collection oriented (in order to answer the research question) but to refine, to test and to validate the case study tool (questionnaire).

\section{Conclusions \& Further Research}

This study is part of a wider research project, whose main objective is to understand the influence of the PLM functionalities on the NFD performances. The methodology used in order to achieve the research goal is case study. In order to get a work methodologically efficient from the research point of view, it is important to design a good research tool, which in this case is a semi-structured questionnaire. This paper shows the results relating to the final phase of the questionnaire design: The Pilot Case. The pilot case has been developed with the aid of Poult (a French biscuits company). Various corporate figures (R\&D, Marketing and Production) have participated in this process, in order to obtain different points of view and a more complete improvement of the instrument. The results of the pilot case helped mostly to better refine it in terms of questions and of structure. In fact, it was decided to move some section of the questionnaire (because it seems to give a better logic sequence) and to eliminate other parts (because they don't add so much added value). Nevertheless, some results have been obtained from the Poult interview, in particular: the most important NFD process phases for Poult are "Study Product Internal Feasibility", "Study Product External Feasibility" and "Manufacture, Launch and Commercialize". Nonetheless, only the phases of "Study Product Internal and External Feasibility" are supported by different PLM functionalities. The Manufacture, Launch and Commercialize activity is measured by different performances but no PLM functionalities are used to support it. It would be interesting to better investigate why they made this choice.

In conclusion, it is possible to say that the proper use of this research tool will allow food companies to: (i) better understand the NFD processes and activities, (ii) define, discover and monitor the NFD performances by giving them a relevance, (iii) understand how the use of PLM tool can support the NFD process and (iv) understand how the PLM functionalities can affect the various activities of the process and as a result the performance associated with them. As future research step, the questionnaire will be submitted to different food companies that are currently using the PLM functionalities (from at least 3 years) and then answers will be analysed and elaborated in order to 
obtain a final answer to this research work. From a scientific point of view, this work will help to fill a gap in literature about the use of the PLM in the food sector (in particular in support of NFD process). Moreover, also the results related to the NFD process performances, NFD process phases and activities and PLM functionalities supporting the NFD process will allow to enrich the contents about these topics, lacking in the scientific literature. Furthermore, from the practitioner point of view, this study will help PLM vendors to understand the food industry vision about their NFD process and performances. On the other hand, food companies will be able to better understand their NFD process, their NFD process performances and how they can use the PLM system to affect their internal performances. Fundamental element to achieve good results from the use of PLM functionalities is the knowledge of the tools. Food companies that want to manage their processes through these capabilities must therefore first of all make sure they know the related potential, in such a way that they can make the most of these functionalities.

\section{$7 \quad$ References}

1. R. J. Lehmann, R. Reiche, and G. Schiefer, "Future internet and the agri-food sector: Stateof-the-art in literature and research," Comput. Electron. Agric., vol. 89, pp. 158-174, 2012.

2. H. Bachev, "Risk management in the agri-food sector," Contemp. Econ., vol. 7, no. 1, pp. 45-62, 2013.

3. M. Fritz and G. Schiefer, "Sustainability in Food Networks," Agriculture, no. September, 2008.

4. J. D. Bloom and C. C. Hinrichs, "Moving local food through conventional food system infrastructure: Value chain framework comparisons and insights," Renew. Agric. Food Syst., vol. 26, no. 1, pp. 13-23, 2011.

5. C. Pinna, M. Taisch, and S. Terzi, "PLM in the Food Industry : an Explorative Empirical Research in the Italian Market Introduction," in IFIP Advances in Information and Communication Technology, 2016, pp. 238-247.

6. Groupe-poult, "GROUPE-Poult,” 2017. [Online]. Available: http://www.groupepoult.com/fr/.

7. P. Overbosch and S. Blanchard, "Principles and Systems for Quality and Food Safety Management," in Food Safety Management: A Practical Guide for the Food Industry, 2013, pp. 537-558.

8. R. Granros, "Regulatory Compliance for Food Safety," Control Engineering, vol. 56, no. 10, p. 50, 2009.

9. F. Jaspers, "Case study research : Some other applications besides theory building," $J$. Purch. Supply Manag., vol. 13, no. 2007, pp. 210-212, 2007.

10. R. K. Yin, Case Study Research Design and Methods, 4th ed., vol. 5. 2009.

11. R. K. Yin, "Case Study Research . Design and Methods," SAGE Publications, vol. 26, no. 1. pp. 93-96, 2003.

12. R. G. . B. Cooper and E. J. . Kleinschmidt, "Winning businesses in product development: The critical success factors," Research-Technology Management, vol. 50, no. 3, pp. 52-66, 2007.

13. M. Montoya-Weiss, "Determinants of new product performance: A review and metaanalysis," J. Prod. Innov. Manag., vol. 11, no. 5, pp. 397-417, Nov. 1994. 